\title{
Availability and Timing of Fathead Minnow Supplementation Influence Largemouth Bass Survival and Production in Rearing Ponds
}

\author{
Matthew J. Ward ${ }^{1}$, Steven R. Chipps ${ }^{2}$ \\ ${ }^{1}$ South Dakota Department of Game, Fish and Parks, Blue Dog Lake State Hatchery, Waubay, USA \\ ${ }^{2}$ U.S. Geological Survey, South Dakota Cooperative Fish and Wildlife Research Unit, McFadden Biostress Laboratory, \\ Department of Natural Resource Management, South Dakota State University, Brookings, USA \\ Email: matthew.ward@state.sd.us
}

How to cite this paper: Ward, M.J. and Chipps, S.R. (2020) Availability and Timing of Fathead Minnow Supplementation Influence Largemouth Bass Survival and Production in Rearing Ponds. Open Journal of Animal Sciences, 10, 337-345.

https://doi.org/10.4236/ojas.2020.103020

Received: March 25, 2020

Accepted: May 15, 2020

Published: May 18, 2020

Copyright (๑) 2020 by author(s) and Scientific Research Publishing Inc. This work is licensed under the Creative Commons Attribution International License (CC BY 4.0).

http://creativecommons.org/licenses/by/4.0/

\begin{abstract}
Adjustments to rearing practices should be justified with increases in production, stocking success, or angler satisfaction. Largemouth bass (Micropterus salmoides) production was assessed between hatchery ponds where fish were restricted to an invertebrate diet or received supplemental fathead minnow (Pimephales promelas) forage during 2015. At harvest, age-0 bass yield was 4.5 times greater and average fish length was $38 \mathrm{~mm}$ longer, in the pond that received fathead minnow. In 2016, a second study evaluated the timing of minnow supplementation that included earlier stockings of small fathead minnow $(<30 \mathrm{~mm})$ compared to delayed supplementation with larger $(>30$ $\mathrm{mm})$ minnows. With earlier supplementation, bass yield was 2.3 times greater and fish averaged $14 \mathrm{~mm}$ longer at harvest. Bass survival was approximately 38\% higher during 2015 when supplementation occurred and 25\% higher during 2016 when minnow supplementation began earlier. Our findings show invertebrate forage was probably limiting bass production in hatchery ponds and supplementing with appropriately-sized fathead minnows increased age- 0 , largemouth bass production.
\end{abstract}

\section{Keywords}

Largemouth Bass Culture, Pond-Rearing, Fathead Minnow Stocking

\section{Introduction}

Largemouth bass (Micropterus salmoides) fisheries provide important recreational opportunities and associated economic benefits in North America [1]. As such, many state and provincial fish hatcheries regularly produce largemouth 
bass for stocking in environments that contain suitable habitat. In South Dakota, USA, stocking advanced-sized (>100 mm TL) largemouth bass (age-1) in the spring generally results in increased survival compared to stocking smaller $(<75$ $\mathrm{mm}$ ), younger (age-0) fish in the fall [2]. Thus, efforts to produce larger, age-1, bass in the spring can enhance supplementation efforts that ultimately lead to greater availability of fish.

A variety of rearing techniques exist to enhance growth and size-at-stocking of largemouth bass that include, reducing fish densities [3], increasing forage by providing fathead minnow (Pimephales promelas) [4], and (or) transferring bass to tanks and converting fish to pelleted diets [5] [6]. In South Dakota, fathead minnows are an abundant resource [7] that have been used to supplement aquatic invertebrate prey during the extensive rearing phase of largemouth bass in hatchery ponds (Personal Communication, Jerry Broughton, Hatchery Manager). Age-0 bass that are large enough to convert to piscivory generally exhibit increased growth compared to those that are not [8]. Moreover, pellet-reared largemouth bass may have difficulty recruiting within lakes compared to bass that are acclimated to capturing live prey fish [9]. Pellet-reared juvenile muskellunge (Esox masquinongy) showed lower post-stocking survival than minnow-reared fish, due to higher predation mortality [10].

The availability and timing of fathead minnow supplementation may have an important influence on age- 0 bass production in hatchery ponds, although the combination of availability and timing has not been well documented. Stocking of fathead minnows during the early rearing phase may provide little benefit to age-0 bass growth, if invertebrate prey are abundant and (or) the ratio of minnow-length to bass-length is too great (i.e., gape limitation). Similarly, minnows may provide limited growth enhancement if stocked too late during the growing season. In this study, we evaluated largemouth bass growth and survival in response to supplemental minnow stockings. We also compared numbers of largemouth bass produced with or without supplemental minnow stockings in the initial study, and then we examined early and late-season minnow stockings compared to late-season only, minnow stockings.

\section{Methods}

Largemouth bass rearing experiments were conducted during 2015 and 2016 at Blue Dog State Fish Hatchery, near Waubay, South Dakota $\left(45^{\circ} 21^{\prime} 30.89^{\prime \prime} \mathrm{N}\right.$, $\left.97^{\circ} 19^{\prime} 03.63^{\prime \prime} \mathrm{W}\right)$. In most years, approximately 100 adult largemouth bass broodstock are allowed to spawn naturally in 0.4 -ha, unlined ponds with each pond receiving 15 to 20 pairs. Age- 0 bass are harvested when fry approach 25 $\mathrm{mm}$ (in total length) and are then stocked into separate, grow-out rearing ponds at reduced densities.

Experiments were conducted in lined, 0.8 -ha rearing ponds $(\mathrm{n}=2)$, that were filled in late June and fertilized with $\sim 85 \mathrm{~kg}$ of alfalfa meal/ha prior to stocking fish on June 29 or 30 . Each year, the same size and number of bass were stocked 
into each pond; overall mean stocking density of age- 0 bass was 6330 fish/ha with a mean total length of $22 \mathrm{~mm}$. Additional fertilizer was applied to all ponds at a rate of $\sim 85 \mathrm{~kg}$ of alfalfa meal/ha at approximately 10 -day intervals for a total of 4 applications per pond.

In 2015, one largemouth bass rearing pond was supplemented with fathead minnow beginning on July 23 and continuing through September 30 (Table 1). An effort was made to stock minnows each weekday if fathead minnows from the previous day appeared to have been consumed (i.e., not visible in the pond). Another bass rearing pond was used as a control and was not supplemented with fathead minnows. Due to the fragile nature of small minnows (13 to $30 \mathrm{~mm} \mathrm{TL}$ ), it was difficult to accurately estimate biomass of minnows stocked into the rearing pond through mid-August (hereafter "early minnow stocking"). However, larger minnows ( $>30 \mathrm{~mm} \mathrm{TL}$ ) stocked after mid-August (hereafter "late minnow stocking") could be quantified, resulting in an estimate of $320 \mathrm{~kg}$ being provided. The size classification for early $(13$ to $30 \mathrm{~mm})$ and late $(>30 \mathrm{~mm})$ minnows was determined based on total length measurements from 100 minnows during each period.

In 2016, we stocked both ponds with fathead minnows, and evaluated the influence of stocking time on largemouth bass performance. One pond received both early (July 14 to August 16) and late (August 16 to harvest) stockings of minnows while the other pond received only late minnow stockings (Table 1). The frequency that minnows were stocked was the same as in 2015. Again, the fragile nature of the early fathead minnows did not allow for quantification, but during the late period, $232 \mathrm{~kg}$ of larger minnows ( $>30 \mathrm{~mm}$ in $\mathrm{TL}$ ) from the same source were provided to both ponds.

During both 2015 and 2016, the same amount of fertilizer was used between pond types, so it is unlikely that any water quality differences affected the results. Pond water temperatures remained above $21^{\circ} \mathrm{C}$ for 62 days in 2015 and 51 days in 2016. In addition, dissolved oxygen concentration was measured weekly when water temperatures exceeded $21^{\circ} \mathrm{C}$ and all concentrations remained above 7.5 $\mathrm{mg} / \mathrm{L}$. Overall climate conditions during these comparisons were typical of July through October for the northern Great Plains of North America with temperatures beginning to decrease during September.

Largemouth bass were harvested from ponds in early (2016) to middle (2015) October by draining ponds and collecting fish in a screened, catch basin. At

Table 1. Timeline for early ( $<30 \mathrm{~mm} \mathrm{TL})$ and late $(>30 \mathrm{~mm}$ TL) fathead minnow supplementation during 2015 and 2016.

\begin{tabular}{cccc}
\hline Year & Treatment & $\begin{array}{c}\text { Early-minnow } \\
\text { stocking period }\end{array}$ & $\begin{array}{c}\text { Late-minnow } \\
\text { stocking period }\end{array}$ \\
\hline 2015 & No minnows & NA & NA \\
2016 & Early- and late-season minnows & July 23 to Aug 15 & Aug 16 to Sept 30 \\
& Larly- and late-season minnows & July 14 to Aug 15 & Aug 16 to Sept 22 \\
\hline
\end{tabular}


harvest, a random sample of 50 bass was collected from each pond and measured for total length $(\mathrm{mm})$ and combined weight $(\mathrm{kg})$. The number of largemouth bass (LMB) in each pond was estimated as,

$$
\mathrm{LMB}=(\text { no.fish } / \mathrm{kg}) \times \text { total weight harvested }(\mathrm{kg}) .
$$

Survival was determined by dividing the number harvested by the number stocked and multiplying by 100 . Based on total length measurements of harvested fish, the percentage of bass within $5 \mathrm{~mm}$ length groups was determined and then extrapolated to the number of bass harvested to develop length-frequency distributions for each pond. We compared the length-frequency distributions of largemouth bass between ponds (each year) using a Kolmogorov-Smirnov two-sample test in Systat 12 (Systat Software, Inc. San Jose, California, USA). Statistical significance was set at $\alpha=0.05$.

\section{Results}

Number of bass harvested and yield were substantially greater in the pond supplemented with minnows compared to the pond without supplementation during 2015 (Table 2). Estimated survival of bass in the minnow-supplemented pond exceeded $100 \%$, likely owing to overestimation of initial stocking densities. Nonetheless, bass survival in the minnow-supplemented pond was notably greater (i.e., 1.5 times) than that observed in the un-supplemented, control pond (Table 2). At harvest, the size-frequency distribution of largemouth bass differed significantly between the minnow-supplemented and the control pond (Kolmogorov-Smirnov test; $\mathrm{D}=0.98 ; \mathrm{P}<0.001$ ), with mean size larger in the minnow-supplemented pond (Figure 1). Nearly all bass (96\%) in the minnow-supplemented pond were greater than $100 \mathrm{~mm}$ in total length at harvest, whereas only $2 \%$ of bass in the non-supplemented minnow pond achieved 100 $\mathrm{mm}$. At harvest, bass length was more variable in the pond that received minnows (Figure 1).

In 2016, number of bass harvested, survival, and yield were all substantially higher in the pond that received both early and late-season minnows (Table 2). At harvest, size structure was significantly larger in the pond that received both early and late minnows $(\mathrm{D}=0.5, \mathrm{P}<0.001)$ and this resulted in an additional

Table 2. Largemouth bass harvest statistics (mean total length $( \pm \mathrm{SE})$ in millimeters, number, percent survival, and total weight in kilograms) for 0.8-hectare, lined ponds during the 2015 and 2016 growing seasons. NA indicates that the estimated survival exceeded $100 \%$.

\begin{tabular}{cccccc}
\hline Year & Treatment & Length & Number & Survival & Weight \\
\hline 2015 & No minnows & $85(1)$ & 3960 & 79.3 & 30 \\
& $\begin{array}{c}\text { Early- and late-season } \\
\text { minnows }\end{array}$ & $123(2)$ & 5900 & NA & 134 \\
& Late-season minnows & $125(2)$ & 2016 & 39.3 & 51 \\
& $\begin{array}{c}\text { Early- and late-season } \\
\text { minnows }\end{array}$ & $139(2)$ & 3334 & 64.9 & 117 \\
\hline
\end{tabular}




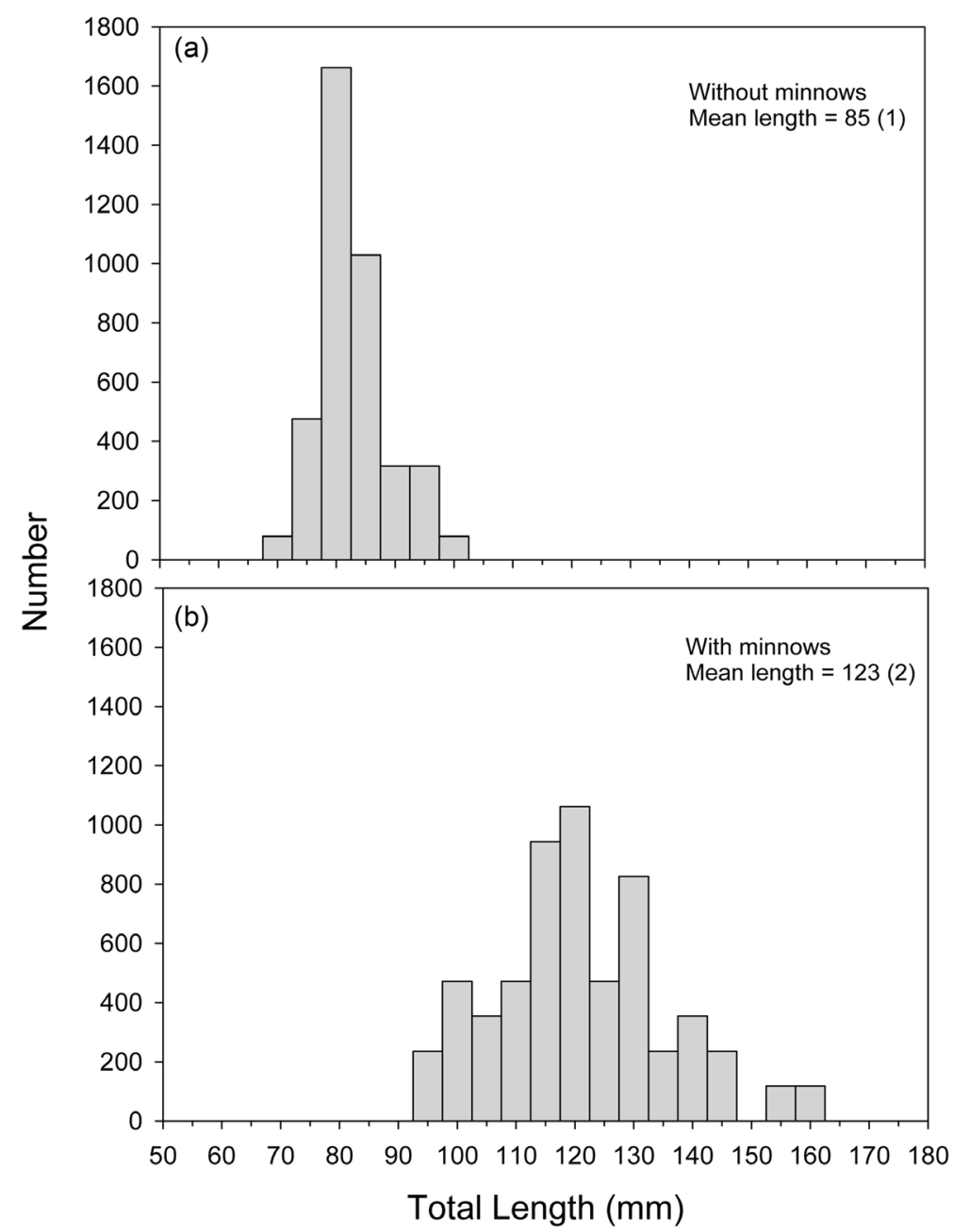

Figure 1. Size frequency distribution of age-0 largemouth bass harvested in 2015 from (a) a pond without fathead minnow supplementation or (b) a pond with fathead minnow supplementation. Largemouth bass mean $( \pm S E)$ length in millimeters is presented for each figure.

2000 bass $\geq 130 \mathrm{~mm}$ being produced (Figure 2). The length range of bass at harvest was similar between both ponds (Figure 2).

\section{Discussion}

We considered these experiments whole-system manipulations that were un-replicated. As such, true cause and effect are difficult to infer. However, the consistency of increased largemouth bass yield with increased fathead minnow supplementation increases the likelihood that these results are repeatable and reduces the concern for lack of treatment replication [11].

The importance of fish prey to the diet of age- 0 largemouth bass in natural systems has been well documented. Post [8] showed that age-0 largemouth bass that were able to switch to, and maintain, piscivory during their first summer of life exhibited growth rates nearly twice that of fish that did not shift until their second summer. Similar findings occurred in this study, with minnow-fed bass 


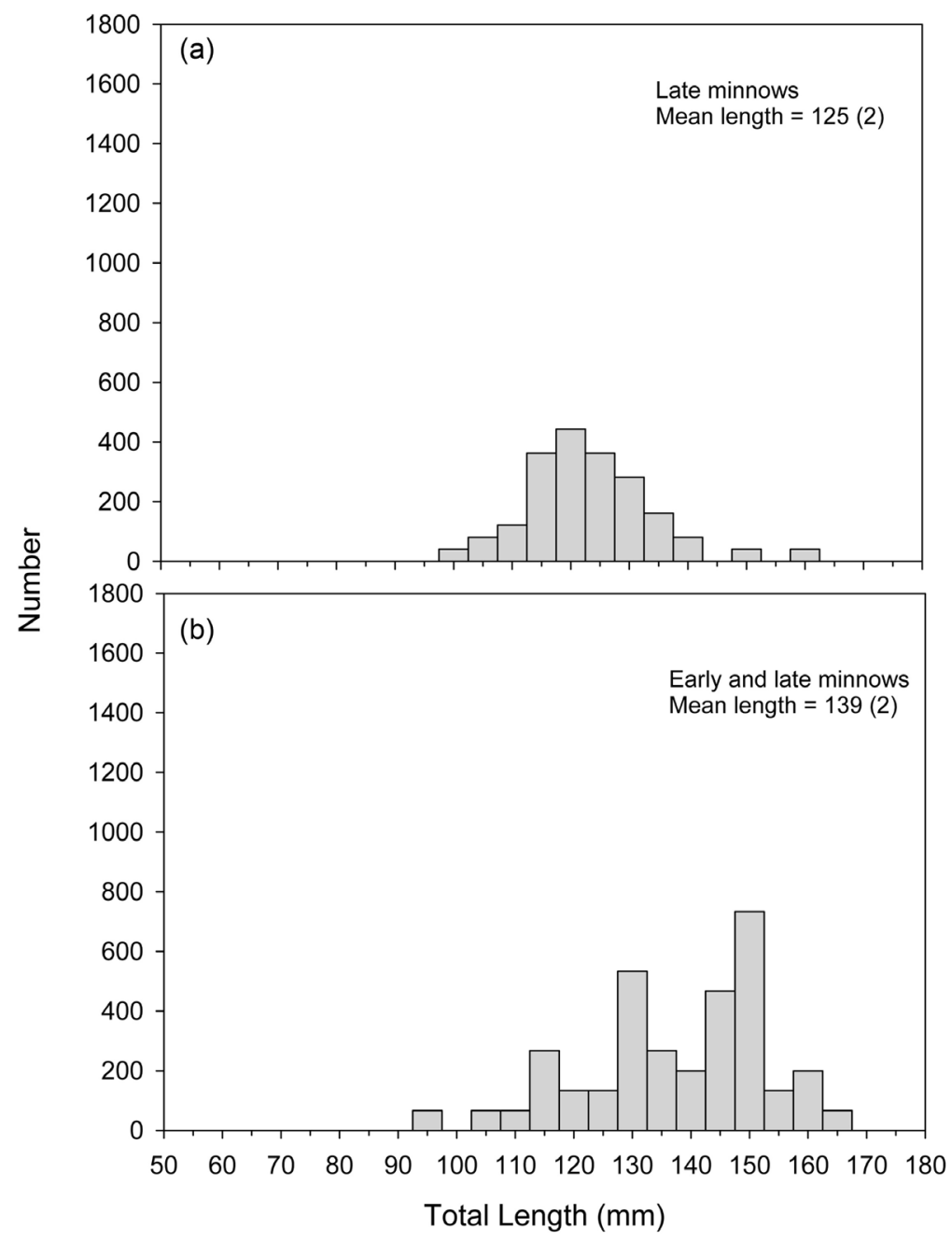

Figure 2. Size frequency distribution of age-0 largemouth bass harvested in 2016 from (a) a pond with late-supplemented minnows or (b) a pond with early- and late-minnow supplementation. Minnows provided during the early-minnow stocking period were less than $30 \mathrm{~mm}$ in total length whereas those provided during the late-minnow stocking were greater than $30 \mathrm{~mm}$. Largemouth bass mean $( \pm \mathrm{SE})$ length in millimeters is presented for each figure.

achieving an average of $38 \mathrm{~mm}$ in additional length and $104 \mathrm{~kg}$ of additional biomass in 2015. In 2016, conversion to early piscivory produced bass that were on average $14 \mathrm{~mm}$ longer and an additional $66 \mathrm{~kg}$ of biomass compared to postponing minnow supplementation. These findings indicate that forage may have been limiting bass production within the hatchery ponds, despite the use of reduced stocking densities of 6200 to 6412 fish/ha compared to historical density of 37,500 fish/ha used at this hatchery [12].

Increasing forage resources through minnow supplementation also increased bass survival within the hatchery ponds. Removing, or delaying, minnow supplementation could have subjected bass to increased mortality, due to either lack of energy reserves, characteristic of smaller-sized fish [13] [14] or cannibalism [8]. Cannibalism among age-0 largemouth bass is a concern and increases when 
size variability exists [15]. Initial variation in bass size at stocking was not determined in our study, but should not have been different because all age- 0 bass originated from the same spawning pond. Reduced survival in 2015, in the pond without minnow supplementation, and in 2016, with delayed supplementation, suggests cannibalism and (or) size-dependent starvation was increased in those ponds [15]. In another study that used a similar stocking density (e.g., 7500 fish/ha) and provided supplemental forage, bass survival averaged 70\% [4]. This is comparable to the survival of bass in 2016 ( 65\%) when minnow supplementation began early and continued for the remainder of the growing season.

The most uniform size structure occurred in the pond that did not receive minnow supplementation during 2015. This suggests the invertebrate forage was consumed evenly by all bass compared to the supplemental minnow forage. Supplementing the ponds with frequent, low density stockings of minnows may have contributed to the increased size variation owing to size-structured piscivory in largemouth bass. Bass that transition more quickly from invertebrates to minnows would have a growth (i.e., size) advantage over others because they are capable of feeding on a progressively larger size of minnow throughout the summer [16].

This experiment showed that the availability and timing of supplemental forage (minnows) can influence largemouth bass production in hatchery ponds during the early rearing phase. Minnow supplementation greatly increased bass size at harvest while also increasing their survival. Laboratory studies, based on handling time and prey selectivity, have shown that for young largemouth bass ( $\leq 75 \mathrm{~mm}$ ) optimal-sized fathead minnow range from 7.5 to $35 \mathrm{~mm}$ [17]. Thus, increasing the early-stocking density of small minnows $(<35 \mathrm{~mm})$ could enhance piscivory among young bass and further increase their size at harvest in rearing ponds [18]. Developing techniques that increase the catch rate (i.e., sampling gear; [19]) or production (e.g., [18]) of small fathead minnow would provide practical solutions to increasing their availability during the early rearing phase, when largemouth bass are smaller than $75 \mathrm{~mm}$.

\section{Acknowledgements}

Special thanks to Blue Dog Hatchery staff including Jerry Broughton, Randy Smidt, Ryan Rasmus, Nathan Pool, and Chad Haabala for collecting fathead minnow, laboratory work, and fish culture duties that allowed for the publication of these data. The South Dakota Cooperative Fish and Wildlife Research Unit is jointly supported by the U.S. Geological Survey, South Dakota State University, and South Dakota Department of Game, Fish \& Parks. Any use of trade, firm, or product names is for descriptive purposes only and does not imply endorsement by the U.S. Government.

\section{Conflicts of Interest}

The authors declare no conflicts of interest regarding the publication of this paper. 


\section{References}

[1] Philipp, D.P. and Ridgway, M.S. (2002) Black Bass: Ecology, Conservation and Management. American Fisheries Society, Bethesda.

[2] Csargo, I.J. (2011) Advanced Largemouth Bass Production and Stock Contribution to Small South Dakota Impoundment Fisheries. Master's Thesis, South Dakota State University, Brookings.

[3] Piper, R.G., McElwain, I.B., Orme, L.E., McCraren, J.P., Fowler, F.G. and Leonard, J.R. (1982) Fish Hatchery Management. U.S. Fish and Wildlife Service, Washington DC.

[4] Martinez, J.G. and Owens, T. (2005) A Comparison of Three Stocking Densities for Rearing 150-mm Florida Largemouth Bass, Micropterus salmoides floridanus, in Ponds. Management Data Series No. 255. Texas Parks and Wildlife, Inland Fisheries Division, Austin.

https://tpwd.texas.gov/publications/pwdpubs/media/pwd rp t3200 1559.pdf

[5] Heidinger, R.C. (2000) A White Paper on the Status and Needs of Largemouth Bass Culture in the North Central Region. North Central Regional Aquaculture Center, White Papers, 4.

http://agrilife.org/fisheries/files/2013/09/A-White-Paper-on-the-Status-and-Needsof-Largemouth-Bass-Culture-in-the-North-Central-Region.pdf

[6] Csargo, I.J., Brown, M.L. and Ward, M.J. (2013) Practical Comparison of Commercial Starter Diets for Feed Training Largemouth Bass Fingerlings. Journal of Applied Aquaculture, 25, 24-34. https://doi.org/10.1080/10454438.2012.749824

[7] Duffy, W.G. (1998) Population Dynamics, Production, and Prey Consumption of Fathead Minnows (Pimephales promelas) in Prairie Wetlands: A Bioenergetics Approach. Canadian Journal of Fisheries and Aquatic Sciences, 54, 15-27. https://doi.org/10.1139/cjfas-55-1-15

[8] Post, D.M. (2003) Individual Variation in the Timing of Ontogenetic Niche Shifts in Largemouth Bass. Ecology, 84, 1298-1310. https://doi.org/10.1890/0012-9658(2003)084[1298:IVITTO]2.0.CO;2

[9] Diana, M.J., Diffin, B.J., Einfalt, L.M. and Wahl, D.H. (2018) Effect of Rearing Experience on the Survival, Growth, and Behavior of Hatchery-Reared Largemouth Bass. North American Journal of Fisheries Management, 38, 794-802. https://doi.org/10.1002/nafm.10175

[10] Wahl, D.H. (1999) An Ecological Context for Evaluating the Factors Influencing Muskellunge Stocking Success. North American Journal of Fisheries Management, 19, 238-248. https://doi.org/10.1577/1548-8675(1999)019<0238:AECFET>2.0.CO;2

[11] Perry, J.A. and Troelstrup Jr., N.H. (1988) Whole Ecosystem Manipulation: A Productive Avenue for Test System Research? Environmental Toxicology and Chemistry, 7, 941-951. https://doi.org/10.1002/etc.5620071111

[12] Broughton, J., Smidt, R., Ward, M., Holm, E. and Rasmus, R. (2009) Blue Dog Lake State Fish Hatchery Annual Production Report. Annual Report No. 09-08. South Dakota Department of Game, Fish and Parks, Pierre.

http://sdsdl-montage.auto-graphics.com/\#/item-details/entities 1239 ?from=search$\underline{\text { results }}$

[13] Oliver, J.D. and Holeton, G.G. (1979) Overwinter Mortality of Fingerling Smallmouth Bass in Relation to Size, Relative Energy Stores, and Environmental Temperature. Transactions of the American Fisheries Society, 108, 130-136. https://doi.org/10.1577/1548-8659(1979)108<130:OMOFSB >2.0.CO;2 
[14] Isely, J.J. (1981) Effects of Water Temperature and Energy Reserves on Overwinter Mortality of Young of the Year Largemouth Bass (Micropterus salmoides). Master's Thesis, Southern Illinois University, Carbondale.

[15] Davis, J.T. and Lock, J.T. (1997) Culture of Largemouth Bass Fingerlings. Southern Regional Aquaculture Center Publication No. 201.

https://agrilifecdn.tamu.edu/wildlife2/files/2010/04/2 Culture of Largemouth Fin gerlings.pdf

[16] Olson, M.H. (1996) Predator-Prey Interactions in Size-Structured Fish Communities: Implications of Prey Growth. Oecologia, 108, 757-763.

https://link.springer.com/article/10.1007/BF00329052

https://doi.org/10.1007/BF00329052

[17] Einfalt, L.M., Parkos, J.J. and Wahl, D.H. (2015) Effect of Predator Size and Prey Characteristics on Piscivory of Juvenile Largemouth Bass. Transactions of the American Fisheries Society, 144, 682-692.

https://doi.org/10.1080/00028487.2015.1027002

[18] Horne, A.N., Stone, N. and Engle, C.R. (2010) Development of New Intensive Hatchery Methods for Rosy Red Fathead Minnows. North American Journal of Aquaculture, 72, 237-251. https://doi.org/10.1577/A09-054.1

[19] Broughton, J. and Potter, K. (2002) South Dakota Baitfish Harvest 2001 Summary. Annual Report No. 03-03. South Dakota Department of Game, Fish and Parks, Pierre. 